Araştırma Makalesi - Research Article

\title{
AISI 1040 çeliğinin tornalanması sonucu oluşan yüzey pürüzlülük değerlerinin RSM ve YSA ile araştırılması
}

\author{
Harun AKKUŞ ${ }^{1 *}$
}

Geliş / Received: 22/10/2019

Revize / Revised: 11/01/2020

Kabul / Accepted: 03/02/2020

ÖZ

Bu çalışmada, Design Expert programında yüzey yanıt metodu (RSM) Box-Behnken tasarımına göre deney listesi oluşturulmuştur. Oluşturulan deney listesine uygun olarak AISI 1040 çeliğinin tornalaması sonucu yüzey pürüzlülük değerleri elde edilmiştir. Elde edilen yüzey pürüzlülük değerleri ile RSM modeli ve yapay sinir ağ (YSA) modeli oluşturulmuştur. RSM modeli ile ikinci dereceden regresyon denklemi, varyans analizi (ANOVA) parametre etkileşimlerinin yüzey pürüzlülüğüne etkisi iki boyutlu kontur grafiği ve üç boyutlu yanıt grafiği, optimum kesme parametreleri incelenmiştir. Matlab programı ile YSA modeli oluşturulmuştur. RSM ve YSA modellerinin tahmin sonuçlarının doğruluğunu araştırmak için üç tane test deneyi belirlenmiştir. Test deneyleri gerçekleştirilmiştir. Daha sonra deneysel Ra, RSM tahmini Ra ve YSA tahmini Ra değerleri kıyaslanmıştır. Bu kıyaslama sonucu RSM modelinin yaklaşık \%90 doğrulukla test sonucunu tahmin ettiği belirlenmiştir.

Anahtar Kelimeler- Tornalama, Yüzey pürüzlülü̈̆̈̈̈, RSM, YSA

1*Sorumlu yazar iletişim: harunakkus@windowslive.com (https://orcid.org/0000-0002-9033-309X) Otomotiv Teknolojisi Programı, Teknik Bilimler Meslek Yüksekokulu, Amasya Üniversitesi, Amasya, Türkiye 


\title{
Investigation of surface roughness values resulting from turning AISI 1040 steel with RSM and ANN
}

\begin{abstract}
In this study, a test list was created according to the Box-Behnken design in the Design Expert program. Surface roughness values were obtained by turning the AISI 1040 steel according to the test list. Respon Surface Methodology (RSM) model and artificial neural network (ANN) model were formed with obtained surface roughness values. The effect of second order regression equation, variance analysis (ANOVA), cutting parameter interactions on surface roughness, two dimensional contour graph and three dimensional response graph, optimum cutting parameters were examined with RSM model. ANN model was created with Matlab program. To test the accuracy of the prediction results of RSM and ANN models, three test experiments were determined. Test experiments were performed. Experimental Ra values, RSM estimation values and ANN estimation values were compared. As a result of this comparison, it was determined that the RSM model predicts the test result with approximately $90 \%$ accuracy.
\end{abstract}




\section{GIRIS}

Katı hal üretim prosesleri geniş ölçüde metal şekillendirme ve metal işlemede sınıflandırılabilir. Metal işleme yöntemlerinden en çok kullanılanlardan bir tanesi tornalamadır [1]. Tornalama işlemleri genellikle silindirik parçalarının işlenmesi için tercih edilen bir yöntemdir. Talaşlı imalatta işlenen parçaların yüzey kalitesi önem arz etmektedir. Tornalama işlemlerinde yüzey pürüzlülüğü kesme hızı, ilerleme, talaş derinliği, soğutma ortamı, takım yarıçapı, malzeme sertliği, tezgah devri gibi parametrelerle doğrudan ilişkilidir. Yüzey kalitesi genellikle ilerlemenin artmasıyla bozulacak, ters etkileri daha büyük takım yarıçapı ile azaltılabilir [2-4].

Birçok çalışmada yüzey pürüzlülüğü ve kesme parametreleri arasındaki ilişki araştırılmaktadır[4]. Kesme parametreleri olarak kesme hızı, ilerleme ve talaş derinliği kullanılmaktadır. Bu parametrelere bağlı yüzey pürüzlülük değerleri elde edilmektedir[6]. Yüzey pürüzlülüğü değerlerini minimize etmek amaçlanmaktadır. Minize etme işlemi deneyler ile sağlanabilmekte ise de uygun parametrelerin optimum noktanın belirlenebilmesi için Taguchi, RSM, gri ilişkisel, çoklu regresyon modelleri, yapay sinir ağı, karınca kolonisi, bulanık mantık gibi yöntemler kullanılmaktadır[7-10]. Optimum kesme parametrelerinin belirlenmesi zaman ve maliyet açısından operatöre kazanç sağlamaktadır.

Optimizasyon, prosesin belirlenen hedefler (yanıtlar) doğrultusunda, bağımsız değişkenlerin birbirleriyle olan etkileşimleri ve bu bağımsız değişkenlerin hedefe (yanıta) olan etkileri de göz önünde bulundurularak bir araya getirilip uygulanması işlemidir[11]. Tornalama işleminde bağımsız değişken olarak kesme hızı, ilerleme, talaş derinliği, kesici uç, malzeme gibi parametreler seçilebilir. Bağımlı değişken olarak ise yüzey pürüzlülüğü, takım aşınması, kesme kuvvetleri, titreşim, akustik emisyon, sıcaklık gibi parametreler seçilebilir[12-15]. Optimizasyon işlemi, hedef fonksiyonu önceden tanımlanmış kriterleri maksimize veya minimize için bağımsız değişkenlerin değiştirilmesini içerir.

YSA insan beyninin sinir ağlarını taklit eden, ağırlıklı bağlantılar aracılığıyla birbirine bağlanan, örneklerden genellemeler yaparak öğrenme yolu ile yeni bilgiler türetebilme, keşfedebilme ve oluşturabilme yeteneğine sahip bilgisayar yazılımlarıdır. YSA tahmin, sınıflandırma, tanıma, teşhis, yorumlama, veri filtreleme ve ilişkilendirme gibi birçok fonksiyonu gerçekleştirir. YSA ekonomi, askeri, sağlık, iletişim, makine, inşaat, otomotiv, uçak gibi birçok uygulamada kullanılmaktadırlar[16]. Talaşlı imalatta YSA modeli oluşturularak ağın eğitimi yapılır. Ağ eğitimi yapıldıktan sonra YSA modelinin ara değerleri tahmini gerçekleştirilerek zaman ve maliyet açısından kazanç sağlanır[17, 18].

Literatürde model kıyaslama ile ilgili birçok çalışma bulunmaktadır[19-21]. Birden fazla tahmin modelinin oluşturulup kıyaslanması mevcut yapı için optimum çözümün hangisi olduğuna karar vererek zaman ve maliyet açısından kazanç elde etmemize yardımcı olur.

Bu çalışmada AISI 1040 çeliğinin tornalanması sonucu oluşan yüzey pürüzlülük değerleri ölçülmüştür. Elde edilen yüzey pürüzlülük değerleri için RSM ve YSA modelleri oluşturulmuştur. RSM ve YSA modelleri kıyaslanmıştır. Yüzey pürüzlülüğü için optimum kesme parametreleri belirlenmiştir.

\section{MATERYAL METOT}

Mevcut deneysel çalışma için işleme koşulları Tablo 1'de verilmiştir. Şekil 1'de deney şeması verilmiştir. 
Tablo 1. Tornalama işlemi için belirlenen şartlar

\begin{tabular}{ll}
\hline \multicolumn{1}{c}{ İşleme Şartları } & \multicolumn{1}{c}{ Tanımlamalar } \\
\hline İş parçası & AISI 1040 \\
İş parçası sertliği & $47 \mathrm{HRc}$ \\
İş parçası ölçüleri & $\varnothing 95 \times 160 \mathrm{~mm}$ \\
İşlem boyu & $110 \mathrm{~mm}$ \\
İşlem tezgahı & ACE Micromatic Designers LT-20C \\
Kesme hızı (m/min) & $215-245-275$ \\
İlerleme (mm/rev) & $0,13-0,26-0,39$ \\
Talaş derinliği (mm) & $1,3-2,6-3,9$ \\
Kesme ortamı & Kuru \\
Kesici uç & Korloy WNMG08408HM \\
Takım tutucu & AKKO MWLNR 2525M08 9120511 \\
Ölçüm değeri & Ortalama yüzey pürüzlülüğü (Ra) \\
Pürüzlülük ölçüm cihazı & Mitutoyo Surftest SJ-210 \\
Sertlik ölçüm cihazı & BMS Digirock RSR \\
Kullanılan programlar & Design Expert, Matlab, Excell \\
Sonuçların değerlendirilmesi & RSM \\
& Yapay sinir ağı \\
\hline
\end{tabular}

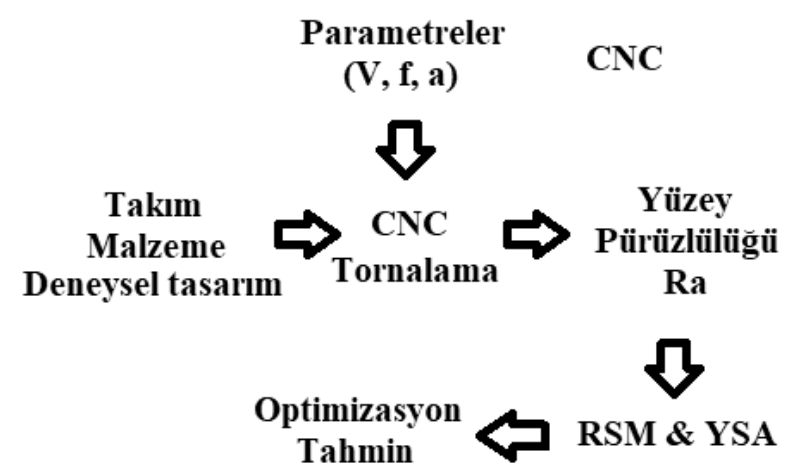

Şekil 1. Deney şeması

Deney tasarımı için Box-Behnken tercih edilmiştir. Box-Behnken tasarımında, deneylerin sayısını ve deney parametrelerini belirlemede kullanılan alfa değeri 1'dir, bu yüzden tasarımı daha kolaydır. Box-Wilson Tasarım farklı deneyler için parametreleri tek tek değiștirirken, Box-Behnken tasarımı aynı anda farklı deneyler için birden fazla parametre değiştirilebilmektedir. Bundan dolayı RSM ile oluşturulan deney tasarımlarında minimum sayıda deney Box-Behnken tasarımı ile elde edilmiştir. Bu deneysel çalışmada olduğu gibi, BoxWilson tasarımlarında deneylerin sayısı 3 seviyeli tasarımlar için 20, Box-Behnken tasarımında ise 15'tir [22]. Kesme parametreleri kesici uç etiketine göre üçer seviye olacak şekilde oluşturulmuştur. Oluşturulan parametreler Tablo 2'de görülmektedir.

Tablo 2. RSM faktörleri

\begin{tabular}{ccccccc}
\hline & Faktör & En düşük & En yüksek & Düşük (-1) & Yüksek (+1) & Orta (0) \\
\hline A & Kesme hıı (m/dk) & 215 & 275 & 215 & 245 & 275 \\
B & İlerleme (mm/dev) & 0,13 & 0,39 & 0,13 & 0,26 & 0,39 \\
C & Talaş derinliği (mm) & 1,3 & 3,9 & 1,3 & 2,6 & 3,9 \\
\hline
\end{tabular}

Box-Behnken tasarımı ile deney sayısı 15 olarak belirlenmiştir. Tablo 2'de Box Behnken yöntemi ile belirlenen deneyler gerçekleştirildikten sonra pürüzlülük değerleri ile ölçülmüştür. Ölçümlere başlanmadan önce yüzey pürüzlülük cihazı kalibre edilmiştir. Ölçümler 120 şer derece olacak şekilde işleme mesafesinin orta 
noktasından üç kere ölçülüp ortalamaları alınmıştır. Deneyler üç tekrar olarak gerçekleştirilmiştir. Box-Behnken deney tasarımı ve ölçülen pürüzlülük değerleri Tablo 3'te verilmiştir.

Tablo 3. Box-Behnken deney tasarımı ve ölçülen yüzey pürüzlülük değerleri

\begin{tabular}{|c|c|c|c|c|}
\hline Deney No & $\begin{array}{c}\text { Faktör } 1 \\
\text { A: V (m/dk) }\end{array}$ & $\begin{array}{c}\text { Faktör } 2 \\
\text { B: } \mathbf{f}(\mathbf{m m} / \mathbf{d e v})\end{array}$ & $\begin{array}{c}\text { Faktör } 3 \\
\text { C: a (mm) }\end{array}$ & $\begin{array}{c}\text { Yanit } \\
\text { Ra }(\mu \mathrm{m})\end{array}$ \\
\hline 1 & 245 & 0,26 & 2,6 & 2,33 \\
\hline 2 & 245 & 0,39 & 3,9 & 4,65 \\
\hline 3 & 275 & 0,39 & 2,6 & 4,43 \\
\hline 4 & 245 & 0,13 & 1,3 & 0,67 \\
\hline 5 & 215 & 0,39 & 2,6 & 3,92 \\
\hline 6 & 215 & 0,13 & 2,6 & 0,55 \\
\hline 7 & 215 & 0,26 & 1,3 & 1,79 \\
\hline 8 & 245 & 0,26 & 2,6 & 2,36 \\
\hline 9 & 245 & 0,13 & 3,9 & 0,65 \\
\hline 10 & 215 & 0,26 & 3,9 & 1,75 \\
\hline 11 & 275 & 0,13 & 2,6 & 0,72 \\
\hline 12 & 245 & 0,39 & 1,3 & 4,52 \\
\hline 13 & 275 & 0,26 & 1,3 & 2,18 \\
\hline 14 & 245 & 0,26 & 2,6 & 2,36 \\
\hline 15 & 275 & 0,26 & 3,9 & 2,38 \\
\hline
\end{tabular}

III. YÜZEY YANIT METODU MODELİ

Elde edilen deneysel sonuçlar için Design Expert 11.1.0.1 paket programı ile istatistiksel analizler yapılmış ve optimum yüzey pürüzlülüğü için uygun ikinci derece regresyon modeli oluşturulmuştur. Design Expert programında hesaplanan katsayılara göre verilen model denklemi aşağıdaki gibi elde edilmiştir.

$R a=2,35-0,2125 * V+1,87 * f+0,0338 * a-0,0850 * V * f+0,06 * V * a+0,0375 * f * a+0,2713 * V^{2}+0,3262 * f^{2}+0,0537 * a^{2}$

Denklemde pozitif değere sahip numerik faktörler cevap değişkeninde artışa neden olurken, negatif değere sahip numerik faktörler cevap değişkeninde azalmaya neden olmaktadır. Denklem katsayılarına göre ilerlemenin yüzey pürüzlülügüne en çok etki eden parametre olduğu belirlenmiştir. İlerlemeden sonra yüzey pürüzlülüğüne sırasıyla talaş derinliği ve kesme hızı olduğu belirlenmiştir. $\mathrm{R}^{2} \% 99,14$ 'dir. $\mathrm{R}^{2}$ değeri 1 'e yakın olduğu için modelin doğruluğunu göstermektedir.

Kesme parametrelerinin yüzey pürüzlülüğüne etkisini belirlemek için varyans analizi (ANOVA) yapıldı. ANOVA sonuçları Tablo 4'te verilmiştir. Elde edilen model denkleminin ANOVA analizinde kontrolü yapıldığında quadratic modelin bu tasarım için uygun olduğu sonucuna varılmıştır. $\mathrm{P}<0,05$ olduğu için oluşturulan model anlamlıdır. Kesme parametreleri ve etkileşimleri için incelendiğinde $\mathrm{p}<0.0001$ olduğu için regresyon denklemi önem arz etmektedir. 
Tablo 4. Yüzey pürüzlülüğü için ANOVA sonuçları

Kaynak Kareler toplamı DF Ortalama kare F-değeri p-değeri

\begin{tabular}{ccccccc}
\hline Model & 97,09 & 9 & 10,79 & $1,02 \mathrm{E}+05$ & $<0.0001$ significant \\
$V$ & 0,0219 & 1 & 0,0219 & 208,11 & $<0.0001$ & \\
$f$ & 95,39 & 1 & 95,39 & $9,05 \mathrm{E}+05$ & $<0.0001$ & \\
$a$ & 0,0581 & 1 & 0,0581 & 551,36 & $<0.0001$ \\
$V^{*} f$ & 0,063 & 1 & 0,063 & 597,45 & $<0.0001$ \\
$V^{*} a$ & 0,0035 & 1 & 0,0035 & 33,57 & 0,0022 \\
$f^{*} a$ & 0,0329 & 1 & 0,0329 & 312,4 & $<0.0001$ \\
$V^{2}$ & 0,0088 & 1 & 0,0088 & 83,21 & 0,0003 \\
$f^{2}$ & 1,51 & 1 & 1,51 & 14330,85 & $<0.0001$ \\
$a^{2}$ & 0,0242 & 1 & 0,0242 & 229,73 & $<0.0001$ \\
Sonuç & 0,0005 & 5 & 0,0001 & & \\
\hline
\end{tabular}

Şekil 2'de kesme parametrelerinin etkisi ve etkileşimleri, iki boyutlu kontur grafiği ve üç boyutlu yanıt grafiği olarak verilmiştir. Şekil 2.a'da Ra-V-f grafiği için iki boyutlu kontur grafiği ve üç boyutlu yanıt grafiği görülmektedir. Şekil 1.a'da yüzey pürüzlülüğü üzerindeki ilerlemenin önemli bir parametre olduğu görülmektedir. İlerleme oranı arttığında yüzey pürüzlülüğünün arttığı görülmektedir. İlerlemenin aşırı etkisine rağmen, kesme hızının yüzey pürüzlülüğü üzerinde çok önemli bir etkisi olmadığı tespit edilmiştir. Kesme hızı ve ilerleme etkileşimine bakıldığında yüzey pürüzlülüğü üzerine etkin parametrenin ilerleme olduğu görülmektedir.

Şekil 2.b'de Ra-V-a grafiği için iki boyutlu kontur grafiği ve üç boyutlu yanıt grafiği görülmektedir. Şekil 2.b incelendiğinde talaş derinliğinin artması yüzey pürüzlülüğünü arttırdığı, fakat kesme hızı arttığı zaman, yüzey pürüzlülügünün azaldığını görülmektedir. Kesme hızı ve talaş derinliği etkileşimine bakıldığında yüzey pürüzlülüğü üzerine etkin parametrenin kesme hızı olduğu görülmektedir.

Şekil 2.c'de Ra-f-a grafiği için iki boyutlu kontur grafiği ve üç boyutlu yanıt grafiği görülmektedir. Şekil 2.c incelendiğinde talaş derinliği ve ilerleme arttı̆ğında arttırılması durumunda yüzey pürüzlülüğünün arttığını görülmektedir. Talaş derinliği ve ilerlemenin etkileşimine bakıldığında yüzey pürüzlülüğü üzerine etkin parametrenin ilerleme olduğu görülmektedir. 


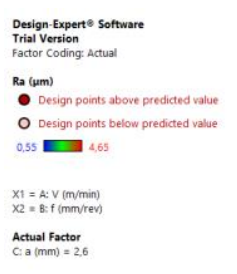

$\frac{\bar{S}_{2}}{2}$

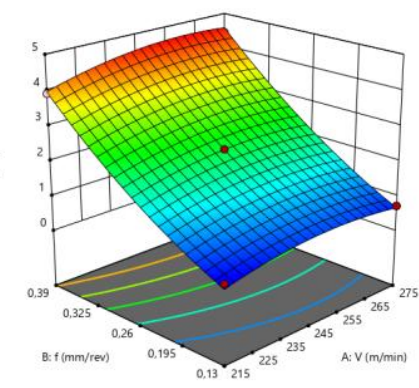

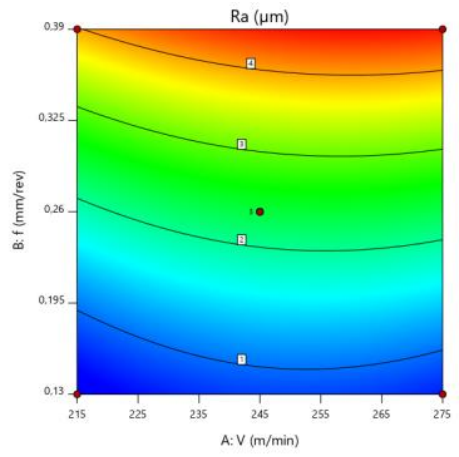
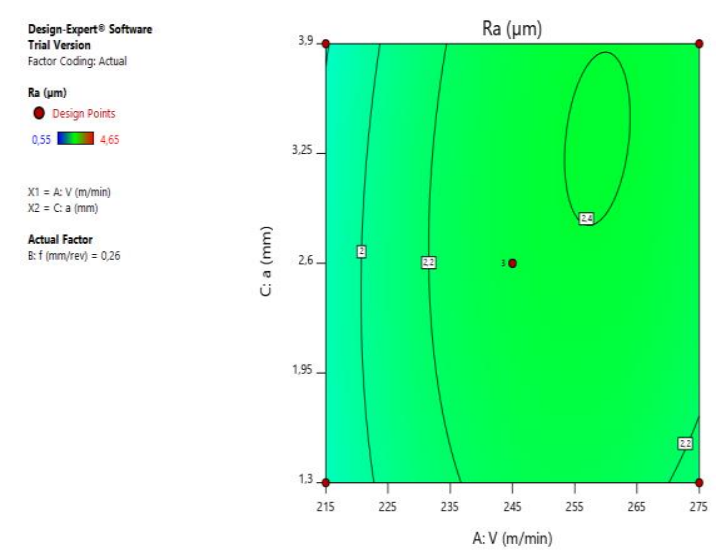

b
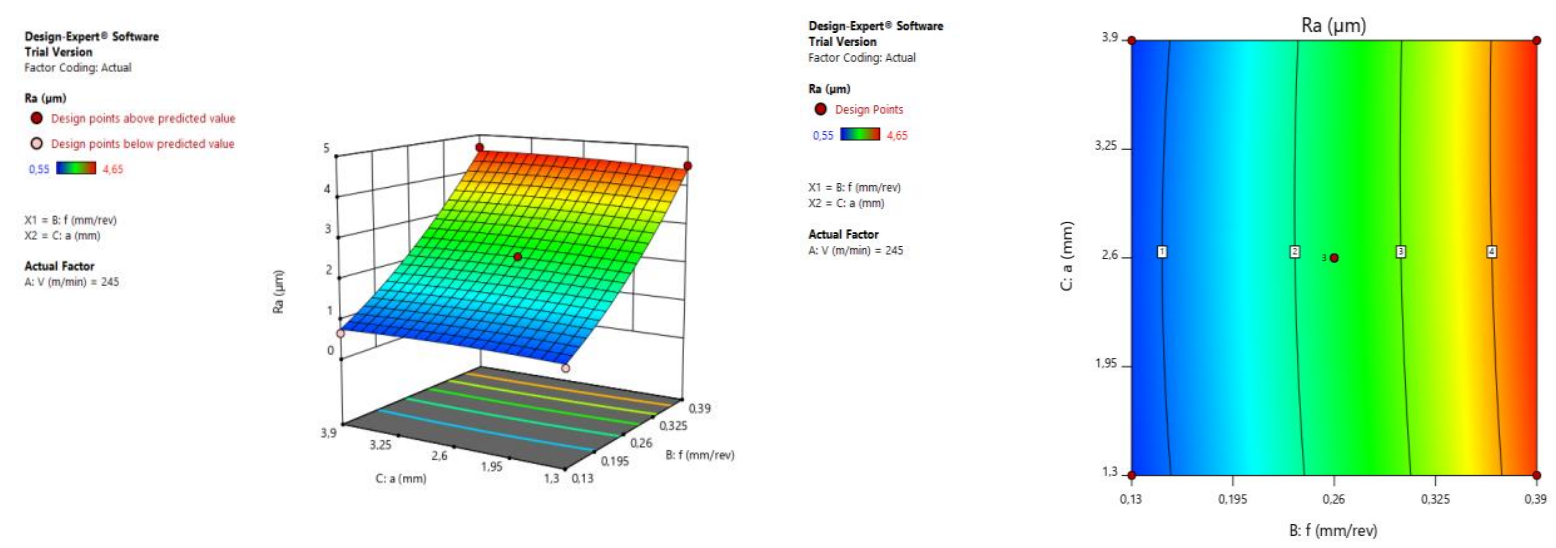

Şekil 2. a) Ra-V-f grafiği b) Ra-V-a grafiği c) Ra-a-f grafiği

Şekil 3'te oluşturulan RSM modelinde deneysel (gerçek) ve tahmin edilen yüzey pürüzlülüğü değerlerinin uyum içerisinde olduğu görülmektedir. 


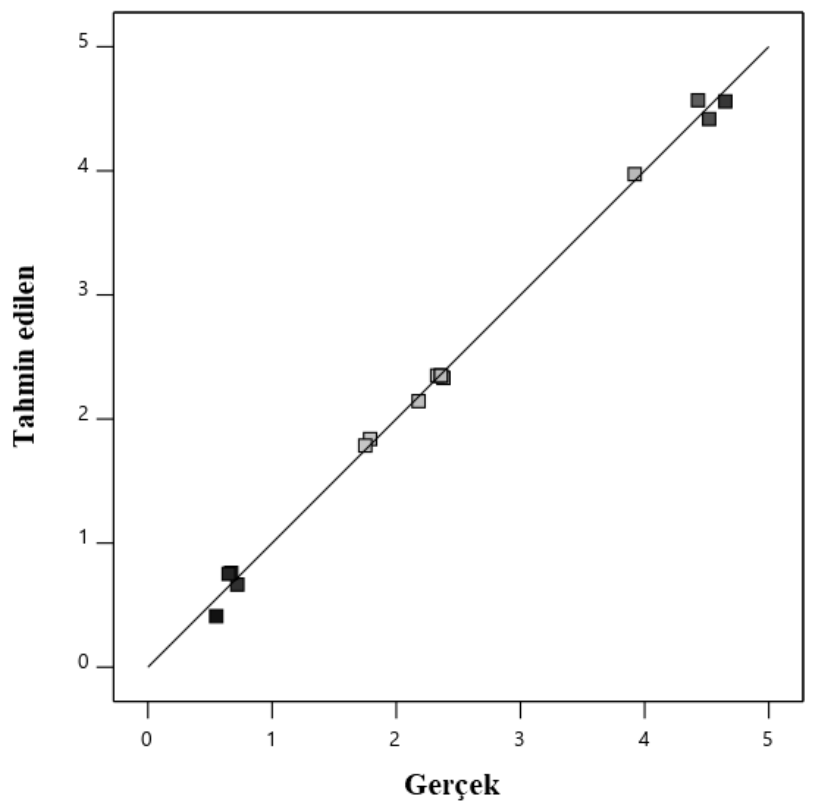

Şekil 3. Deneysel ve tahmin edilen yüzey pürüzlülüğü

Şekil 4 incelendiğinde oluşturulan yüzey cevap metodunda optimum pürüzlülük değerinin elde edildiği noktalar belirlenmiştir. Şekildeki grafikler incelendiğinde kesme hızı yaklaşık $215 \mathrm{~m} / \mathrm{dk}$, ilerleme yaklaşık 0,26 $\mathrm{mm} / \mathrm{dev}$, talaş derinliği ise yaklaşı 3,9 mm olarak belirlenmiştir. Belirlenen kesme parametreleri için yüzey pürüzlülük değeri yaklaşık $1,78 \mu \mathrm{m}$ olduğu görülmektedir.
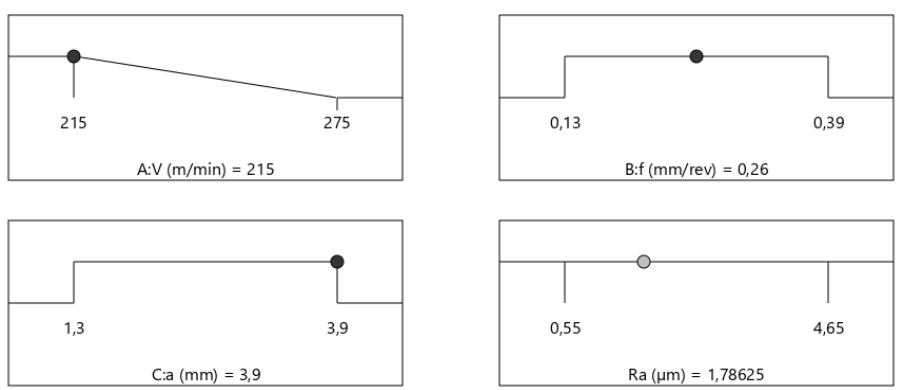

Şekil 4. Yüzey pürüzlülüğünün minimum olduğu noktalar

\section{YAPAY SINIR AĞI MODELİ}

Matlab programının Neural Network Toolboxes(nntool) sayesinde yapay sinir ağ1 modeli oluşturulmuştur. Oluşturulan modelde üç giriş ve bir çıkış bulunmaktadır. Giriş değişkenleri olarak kesme hızı, ilerleme ve talaş derinliği değerleri alınmıştır. Çıkış değişkenleri olarak da Ra değerleri alınmıştır. Şekil 5'te oluşturulan yapay sinir ağı modeli verilmiştir. Yapay sinir ağının eğitiminde Design Expert ile oluşturulan deney listesi sonucu elde edilen deney listesi ve ölçülen Ra değerleri kullanılmıştır. Yapay sinir ağının ezberleme olayını engellemek için deneysel test tahmin verileri eğitime dahil edilmemiştir. A $\breve{g}$ mimarisi, ăg yapısı, düğüm sayısı ve öğrenme derecesi deneme yanılma ile en iyi sonucu veren seçilmiştir. 


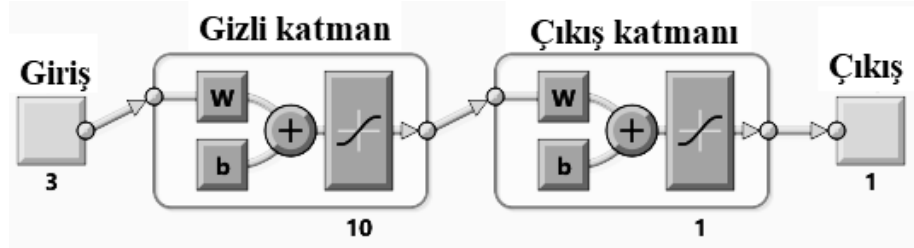

Şekil 5. Oluşturulan YSA modeli

Yapay sinir ağının eğitimi ileri beslemeli geriye yayılım algoritmasının (feedforward backprop) Levenberg-Marquardt (LM) eğitim fonksiyonu ve tansigmoid aktivasyon fonksiyonu kullanılarak gerçekleştirilmiştir. Doğrusal olmayan sistemlerin modellenmesinde en iyi sonuçlar sigmoid aktivasyon fonksiyonu kullanılarak elde edilmektedir.

Şekil 6 incelendiğinde oluşturulan ağ modeli sayesinde yapılan eğitimde gerçek ve tahmin edilen değerler arasındaki ilişki verilmiştir. Eğitim için R değeri 0,99933 olduğu görülmektedir. Bu değer tahminin eğitim verilerine yakınsandığını göstermektedir.

Ĕğitim : R=0.99933

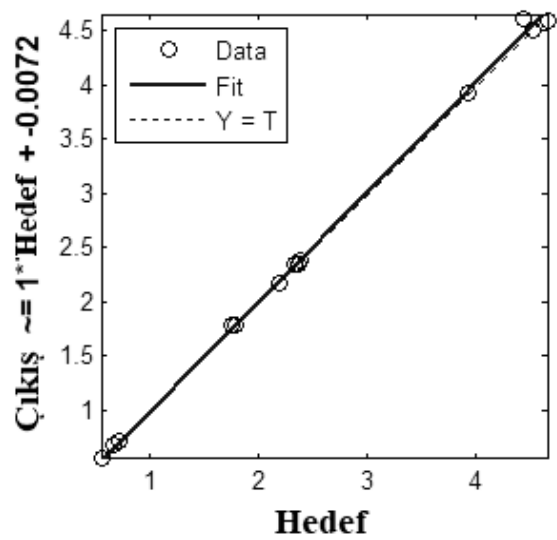

Test: $\mathbf{R}=0.99997$

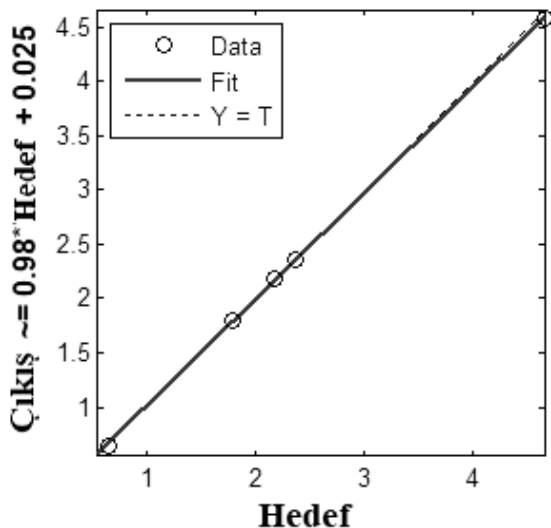

Değer : R=1

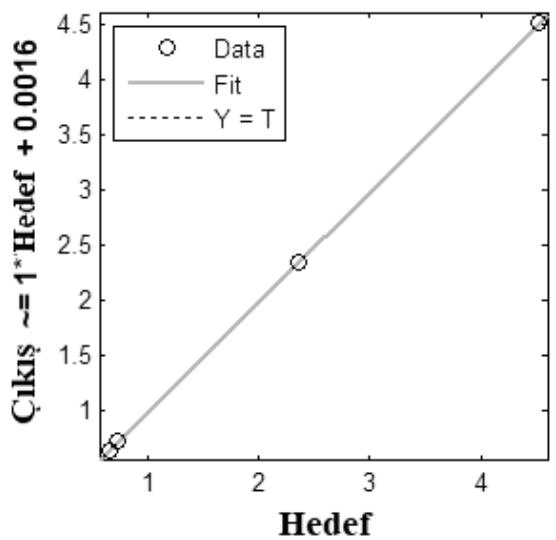

Hepsi : R= 0.99943

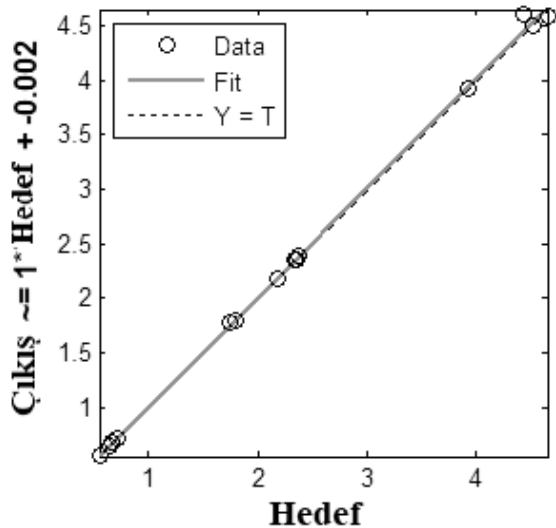

Şekil 6. Yüzey pürüzlülüğü için lineer regresyon grafiği 


\section{RSM VE YSA SONUÇLARININ KIYASLANMASI}

RSM ve YSA modellerinin tahminini kıyaslamak için ara değerler belirlenerek deney listesi oluşturulmuştur. Torna tezgahında oluşturulan listeye göre deneyler gerçekleştirilmiştir. Bu deneyler sonucu oluşan yüzey pürüzlülük değerleri ölçülmüştür. Design Expert'e oluşturulan RSM modeli ile bu test deney listesi için tahmin sonucu Ra değerleri belirlenmiştir. Matlab programında YSA eğitimi tamamlandıktan sonra test deney listesi için YSA tahmini Ra değerleri belirlenmiştir. Tablo 5'te test parametreleri, deney sonuçları, RSM tahmini ve YSA tahmini sonuçları verilmiştir. Şekil 7'de deney sonucu, RSM tahmini ve YSA tahmini grafik olarak verilmiştir. Şekil incelendiğinde deney sonucu Ra ve RSM model tahmini Ra değerlerinin paralel olduğu, YSA tahmin modelinin ise paralel olmadığ 1 görülmektedir.

Tablo 5. Test deney listesi, deney sonucu Ra, RSM tahmini Ra ve YSA tahmini Ra

\begin{tabular}{ccccccc}
\hline Test No & $\mathbf{V}(\mathbf{m} / \mathbf{m i n})$ & $\mathbf{f}(\mathbf{m m} / \mathbf{d e v})$ & $\mathbf{a}(\mathbf{m m})$ & Deneysel Ra $(\boldsymbol{\mu m})$ & RSM tahmini Ra $(\boldsymbol{\mu m})$ & YSA tahmini Ra $(\boldsymbol{\mu m})$ \\
\hline $\mathbf{1}$ & 270 & 0,2 & 3,5 & 1,55 & 1,53 & 1,03 \\
$\mathbf{2}$ & 220 & 0,3 & 3 & 2,61 & 2,55 & 2,55 \\
$\mathbf{3}$ & 250 & 0,15 & 2 & 1,12 & 1,01 & 0,71 \\
\hline
\end{tabular}

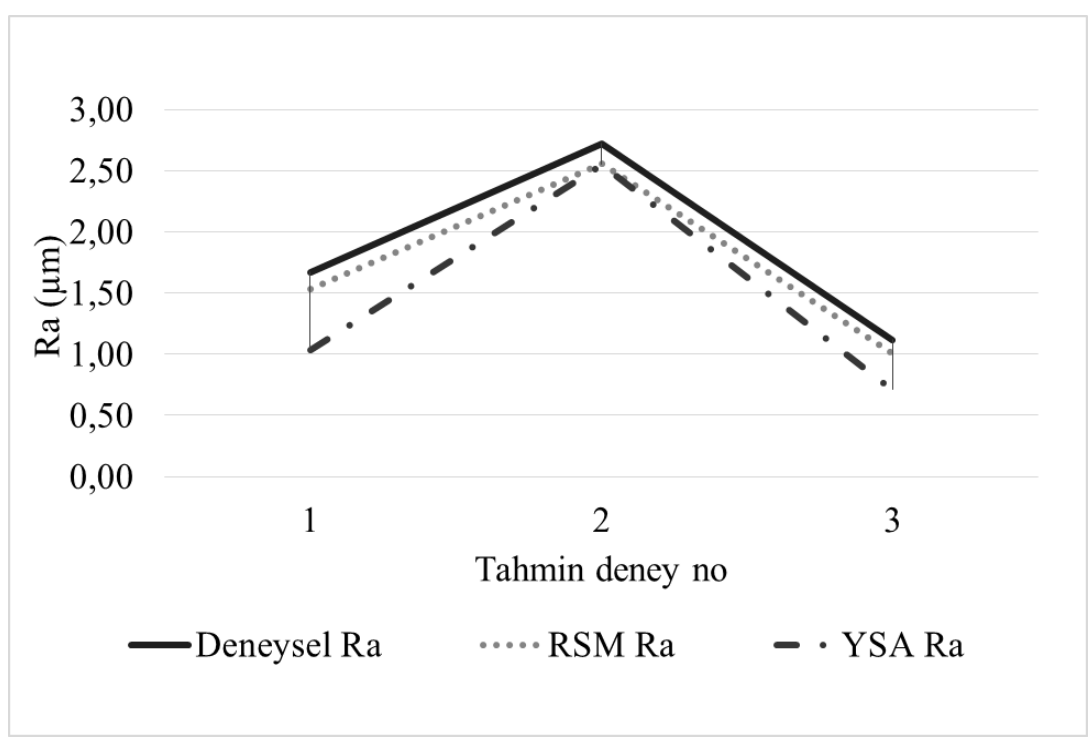

Şekil 7. Deney sonucu Ra, RSM tahmini Ra ve YSA tahmini Ra

RSM ve YSA sonuçları için mutlak \% hata hesabı şu şekilde yapılmıştır.

Fark $=$ Test deneyi-Tahmin modeli

$\%$ hata $=(100 *$ Fark $) /$ Test deneyi

Tablo 6'da RSM ve YSA tahmini elde edilen model sonuçlarının deney sonuçları kıyaslaması sonucu hesaplanan \% hata değerleri verilmiştir. Tabloya göre RSM modelinin deney sonuçlarını yaklaşık \%90 doğrulukla tahmin ettiği görülmektedir. Tabloya göre YSA modelinin deney sonuçlarını yaklaş1k \%62 doğrulukla tahmin ettiği görülmektedir. Bu sonuçlara göre RSM modelinin YSA modeline göre deney sonuçlarına daha yakın bir tahminde bulunduğu sonucuna varılmıştır. Siddique ve ark. yapmış oldukları 
çalışmada RSM modeli ve YSA modelini kıyaslamış, çalışmalarında RSM modelinin YSA modelinden daha yüksek doğrulukla deney sonuçlarını tahmin ettiği sonucuna varmışlardır [22].

Tablo 6. RSM ve YSA modellerinin tahmin hataları

\begin{tabular}{lccc}
\hline Test No & $\mathbf{1}$ & $\mathbf{2}$ & $\mathbf{3}$ \\
\hline RSM \% mutlak hata & 8,38 & 5,88 & 9,82 \\
YSA \% mutlak hata & 38,32 & 6,25 & 36,61 \\
\hline
\end{tabular}

\section{SONUÇLAR}

Bu çalışmada AISI 1040 çeliğinin tornalanması sonucu oluşan yüzey pürüzlülük değerleri incelenmiştir. Kesme parametreleri olarak kesme hızı, ilerleme ve talaş derinliği belirlenmiştir. Belirlene kesme parametrelerine göre deney listesi Design Expert programı kullanılarak RSM Box-Behnken tasarımı ile 15 deney belirlenmiştir. Bu deneyler sonucu Ra değerleri ölçülmüştür.

Ölçülen Ra değerleri Design Expert programı ile RSM modeli oluşturulmuştur. RSM modeli ile ikinci dereceden regresyon denklemi, parametre etkileşimlerinin yüzey pürüzlülüğüne etkileri incelenmiştir. RSM modeli sonucunda en etki parametrenin ilerleme olduğu sonucuna varılmıştır. RSM modeli ile kesme parametrelerinin optimizasyonu gerçekleştirilmiştir. Bu optimizasyon sonucu kesme hızı yaklaşık $215 \mathrm{~m} / \mathrm{dk}$, ilerleme yaklaşı $0,26 \mathrm{~mm} / \mathrm{dev}$, talaş derinliği ise yaklaşık $3,9 \mathrm{~mm}$ olarak belirlenmiştir. Belirlenen kesme parametreleri için yüzey pürüzlülük değeri yaklaşı $1,78 \mu \mathrm{m}$ olarak bulunmuştur.

Matlab R2013a programı ile de YSA modeli oluşturulmuştur. Oluşturulan RSM modeli ve YSA modelinin sonuçları ne doğrulukta tahmin ettiğini görmek için üç tane test parametresi belirlenip deneysel olarak Ra sonuçları belirlenmiştir.

RSM ve YSA modelleri sonucu test parametrelerine uygun Ra sonuçları elde edilmiştir. Daha sonra deneysel Ra, RSM tahmini Ra ve YSA tahmini Ra sonuçları kıyaslanmıştır. Bu kıyaslama sonucu RSM modeli yaklaşık \%90, YSA modeli ise yaklaşık \%62 doğrulukla tahmini gerçekleştirmişlerdir. Bu tahmin sonucunda RSM modelinin YSA modelinden daha iyi tahmin gerçekleştirdiği sonucuna varılmıştır.

\section{KAYNAKLAR}

1. Sahoo, A., Rout, A., Das, D. (2015). Response surface and artificial neural network prediction model and optimization for surface roughness in machining. International Journal of Industrial Engineering Computations, 6(2), 229-240.

2. Agrawal, A., Goel, S., Rashid, W. B., \& Price, M. (2015). Prediction of surface roughness during hard turning of AISI 4340 steel (69 HRC). Applied Soft Computing, 30, 279-286.

3. Zhang, P., Liu, Z. (2016). Modeling and prediction for 3D surface topography in finish turning with conventional and wiper inserts. Measurement, 94, 37-45.

4. Khorasani, A., Yazdi, M. R. S. (2017). Development of a dynamic surface roughness monitoring system based on artificial neural networks (ANN) in milling operation. The International Journal of Advanced Manufacturing Technology, 93(1-4), 141-151.

5. Butola, R., Ali, P., Khanna, V. (2017). Effecton Surface Properties of mild steel during dry turning \& wet turning on lathe. Materials Today: Proceedings, 4(8), 7892-7902.

6. Debnath, S., Reddy, M. M., Yi, Q. S. (2016). Influence of cutting fluid conditions and cutting parameters on surface roughness and tool wear in turning process using Taguchi method. Measurement, 78, 111-119. 
7. Thamizhmanii, S., Saparudin, S., Hasan, S. (2007). Analyses of surface roughness by turning process using Taguchi method. Journal of Achievements in Materials and Manufacturing Engineering, 20(1-2), 503-506.

8. Meddour, I., Yallese, M. A., Bensouilah, H., Khellaf, A., \& Elbah, M. (2018). Prediction of surface roughness and cutting forces using RSM, ANN, and NSGA-II in finish turning of AISI 4140 hardened steel with mixed ceramic tool. The International Journal of Advanced Manufacturing Technology, 1-19.

9. Selvaraj, D. P. (2018). Optimization of surface roughness of duplex stainless steel in dry turning operation using Taguchi technique. Materials Physics and Mechanics, 40, 63-70.

10. Moganapriya, C., Rajasekar, R., Ponappa, K., Venkatesh, R., Jerome, S. (2018). Influence of coating material and cutting parameters on surface roughness and material removal rate in turning process using Taguchi method. Materials Today: Proceedings, 5(2), 8532-8538.

11. Koç, B., Kaymak-Ertekin, F. (2010). Response surface methodology and food processing applications. GIDA-Journal of Food, 35(1), 63-70.

12. Lin, W. S., Lee, B. Y., Wu, C. L. (2001). Modeling the surface roughness and cutting force for turning. Journal of Materials Processing Technology, 108(3), 286-293.

13. Li, X. (2002). A brief review: acoustic emission method for tool wear monitoring during turning. International Journal of Machine Tools and Manufacture, 42(2), 157-165.

14. Labidi, A., Tebassi, H., Belhadi, S., Khettabi, R., Yallese, M. A. (2018). Cutting Conditions Modeling and Optimization in Hard Turning Using RSM, ANN and Desirability Function. Journal of Failure Analysis and Prevention, 18(4), 1017-1033.

15. Panda, A., Sahoo, A. K., Rout, A. K., Kumar, R., Das, R. K. (2018). Investigation of Flank Wear in Hard Turning of AISI 52100 Grade Steel Using Multilayer Coated Carbide and Mixed Ceramic Inserts. Procedia Manufacturing, 20, 365-371.

16. Tasdemir, Ş., Neşeli, S., Yaldız, S. (2009). Prediction of surface roughness on turning with Artificial Neural Network. Journal of Engineering and Architecture Faculty of Eskişehir Osmangazi University, 22(9), 65-75.

17. Kumar, R., Chauhan, S. (2015). Study on surface roughness measurement for turning of Al 7075/10/SiCp and Al 7075 hybrid composites by using Response Surface Methodology (RSM) and Artificial Neural Networking (ANN). Measurement, 65, 166-180.

18. Asiltürk, I., Çunkaş, M. (2011). Modeling and prediction of surface roughness in turning operations using artificial neural network and multiple regression method. Expert Systems with Applications, 38(5), 58265832.

19. Karabulut, Ş. (2015). Optimization of surface roughness and cutting force during $\mathrm{AA} 7039 / \mathrm{Al}_{2} \mathrm{O}_{3}$ metal matrix composites milling using neural networks and Taguchi method. Measurement, 66, 139-14.

20. Arapoğlu, R. A., Sofuoğlu, M. A., Orak, S. (2017). An ANN-based method to predict surface roughness in turning operations. Arabian Journal for Science and Engineering, 42(5), 1929-1940.

21. Mondal, N., Mandal, S., Mandal, M. C. (2020). FPA based optimization of drilling burr using regression analysis and ANN model. Measurement, 152, 107327.

22. Siddique, R. A., Dilwar, F., Nayeem, R. K. (2018). Experimental investigation of the effect of cutting parameters on cutting temperature using RSM and ANN in turning AISI1040. GSJ, 6(8). 